\title{
Quiste Epidérmico Gigante de Región Perianal: Reporte de un Caso
}

\author{
Ignacio F. Ramallo, ${ }^{1}$ José I. Pitaco, ${ }^{1}$ Daniel Crescenti, ${ }^{1}$ Ángel M. Minetti ${ }^{2}$ \\ ${ }^{1}$ Sector de Coloproctología, Servicio de Cirugía General, Sanatorio Trinidad de Quilmes, Buenos Aires. \\ ${ }^{2}$ Encargado de Sector de Coloproctología, Servicio de Cirugía General, Sanatorio Trinidad de Quilmes, Buenos Aires, Argentina. \\ Profesor Adjunto de Cirugía de la Facultad de Medicina, Universidad de Buenos Aires.
}

\begin{abstract}
RESUMEN
Introducción: Quiste epidermoide de inclusión es una lesión dérmica benigna frecuente, predominante en hombres de 30 40 años, originada por secuestro de restos epidérmicos, oclusión pilosebácea o implantación traumática de elementos epiteliales en la dermis.

Caso clínico: Paciente femenino de 75 años de edad la cual presenta tumoración perineal de 4 años de evolución, con aumento progresivo en el último año ocasionando disconfort. Resonancia magnética nuclear, muestra lesión quística. Escisión quirúrgica incluyendo capsula en su totalidad. Anatomía patológica, quiste de inclusión epidérmica. Control a los 6 meses sin evidencia de recidiva.

Conclusión: El quiste epidérmico gigante de inclusión perineal es raro, por lo cual hay que descartar otras patologías similares. El tratamiento quirúrgico debe evitar la escisión fraccionada e incluir la capsula en forma completa, de lo contrario la recidiva es una constante.
\end{abstract}

Palabras claves: Quiste Epidermoide de Inclusión; Quiste Infundibular Pilosebáceo; Quiste Gigante Perineal; Tumor Perianal

\section{ABSTRACT}

Introduction: The epidermoid inclusion cyst is a frequent benign dermal lesion, predominantly in men aged 30-40, caused by sequestration of epidermal remains, pilosebaceous occlusion or traumatic implantation of epithelial elements in the dermis. Case report: A 75-year-old female patient who has 4 years of evolution perineal tumor with a progressive increase in size in the last year causing discomfort. MRI shows a cyst lesion. Surgical excision including capsule. Pathological anatomy, epidermoid inclusion cyst. Following at 6 months without evidence of recurrence.

Conclusion: The giant epidermoid cyst of perineum is rare, therefore we must rule out other similar pathologies. Surgical treatment should avoid fractional excision and include the capsule completely, otherwise recurrence is a constant.

Keywords: Epidermoid Inclusion Cyst; Pilosebaceous Infundibular Cyst; Giant Perineal Cyst; Perianal Tumor

\section{INTRODUCCIÓN}

El quiste epidermoide de inclusión es una lesión dérmica benigna frecuente, la cual se localiza habitualmente en cara, cuello y tronco, siendo rara en región perineal, extremidades, hueso y mama. ${ }^{1-3}$

Es más prevalente en hombres 2:1 entre los 30-40 años de edad, presentándose como lesión aislada, pequeña de 1-4 cm, asintomática, de crecimiento lento. En ocasiones por inflamación, infección o más raramente malignización aumentan de tamaño, produciendo dolor, ulceración y síntomas locales por compresión.

Aquellas de larga data pueden presentar calcificaciones internas o reacción de cuerpo extraño. ${ }^{2-5}$

\section{CASO CLÍNICO}

Mujer de 75 años, consulta por tumor perineal de 4 años de evolución, con disconfort y aumento de tamaño en el último año.

Antecedentes de hipertensión arterial, diabetes y drenaje de absceso perianal hace 5 años.

Ignacio F.Ramallo

ramalloignaciof@gmail.com

Recibido: Septiembre de 2019. Aceptado: Febrero de 2020
En el examen físico, IMC $30 \mathrm{~kg} / \mathrm{m} 2$, prolapso vaginal que emerge por fuera del introito. Sobre el margen anal, cuadrante posterior derecho, asimetría de $5 \mathrm{~cm}$ de diámetro, blanda y móvil a planos profundos (fig. 1).

\section{Resonancia nuclear magnética}

Formación perianal de $10 \times 6 \mathrm{~cm}$, hipointensa en T1, hiperintensa en T2, lobulada con finos tabiques en su interior (fig. 2).

\section{Operación}

Anestesia raquídea, posición de litotomía, se realiza incisión arciforme sobre lesión a $3 \mathrm{~cm}$ del margen anal de 10 $\mathrm{cm}$. Disección hasta pared de quiste y exéresis del mismo. Cierre del lecho con drenaje laminar.

Alta hospitalaria a las 48 horas. A los 7 días postoperatorio dehiscencia parcial de herida. Cierre completo a los 15 días. Control a 6 meses sin evidencia de recidiva.

\section{Anatomía patológica}

Macroscopía, quiste de aspecto fibroadiposo de $9,5 \times 5 \mathrm{~cm}$ (fig. 3). Microscopia, pared quística compuesta por epitelio plano estratificado con células gigantes de reacción de cuerpo extraño. Relleno de bandas laminares de queratina. 


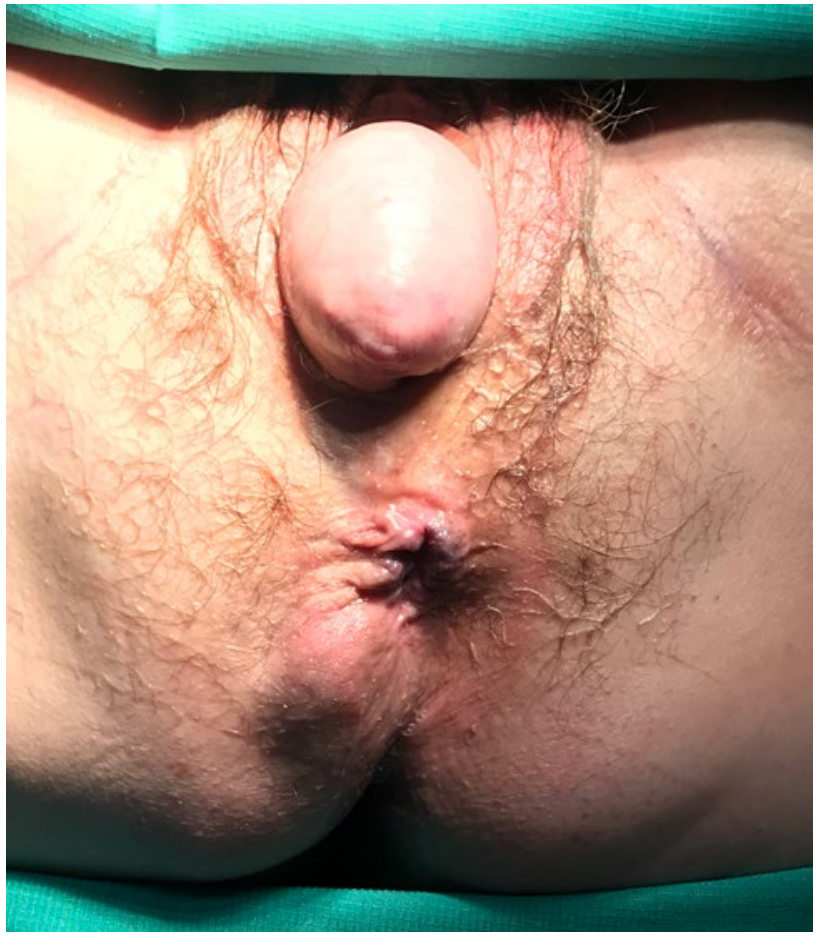

Figura 1: Examen físico en posición de litotomía. Se observa en el cuadrante posterior derecho, asimetría ocasionada por quiste, por arriba, por afuera del introito vaginal se observa prolapso vaginal total.

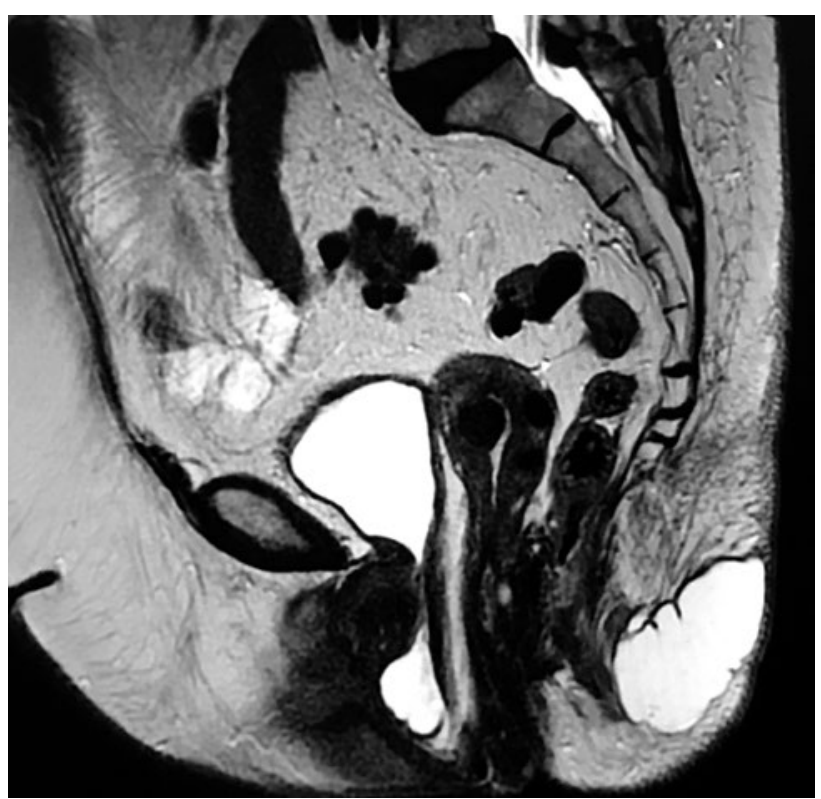

Figura 2: Resonancia nuclear magnética. Corte sagital de pelvis en T2, se evidencia formación hiperintensa lobulada con finos tabiques en su interior.

\section{DISCUSIÓN}

El quiste epidérmico de inclusión de región perineal es raro, puede involucrar escroto, pene, ano, vagina e incluso extenderse a pelvis o recto.

Se forman por secuestro de restos epidérmicos, oclusión pilosebácea o implantación traumática de elementos epiteliales en la dermis. Histopatológica-

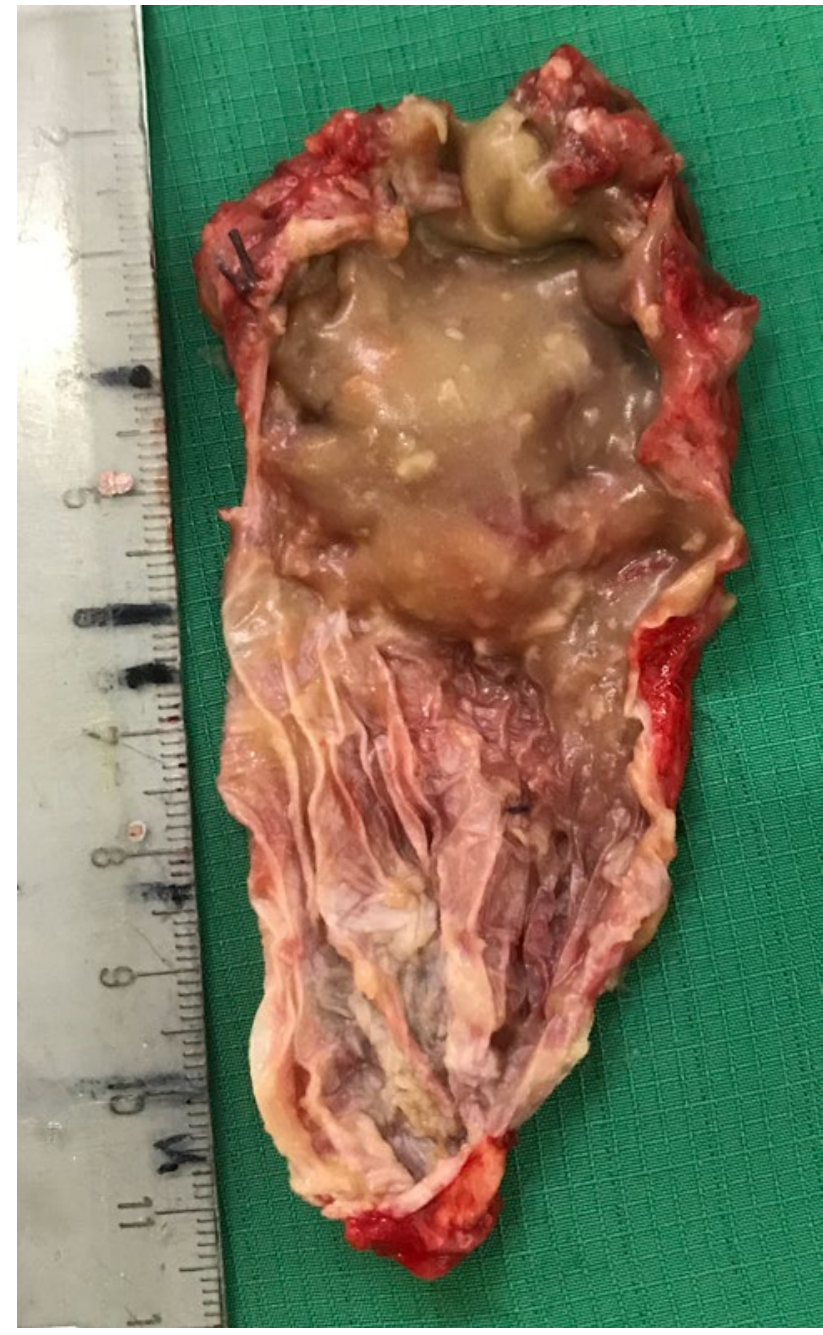

Figura 3: Anatomía Patológica. Macroscopía, se observa el quiste con contenido en su interior de aspecto sebáceo.

mente, está revestido por epitelio escamoso estratificado y se halla relleno de bandas laminadas de queratina.

La mayoría se diagnostican mediante el examen físico, aunque, al presentar gran tamaño, se debe realizar diagnóstico diferencial con lipoma, quiste dermoide, tricolemomas, entre otros.

En la ecografía se visualiza como lesión bien defini$\mathrm{da}$, homogénea, hipoecoica con refuerzo posterior, pudiendo presentar finos tabiques en su interior. Características similares se pueden observar en la tomografía, mientras en resonancia son hiperintensos en T2, hipointensos en T1.

Dejado a su libre evolución, la infección es una complicación frecuente que obliga al tratamiento antibiótico y en ocasiones drenaje quirúrgico.

El tratamiento definitivo es la resección no fragmentada y completa de su pared, de lo contrario es frecuente la recidiva. 


\section{BIBLIOGRAFÍA}

1. Turkay R, Caymaz I, Yildiz B, Livaoglu A, Turkey B, Bakir B. A rare case of epidermoid cyst of perineum: diffusion-weighted MRI and ultrasonography findings. Radiol Case Rep 2013; 8: 593.

2. Ali SA, Tahir SM, Memon AS, Dahri AA. Epidermoid inclusion cyst of the perineum-a rare case report in a 50 years old male. J Ayub Med Coll Abbottabad 2009; 21: 179-80.

3. Hong SH, Chung HW, Choi JY, Koh YH, Choi JA, Kang HS. MRI findings of subcutaneous epidermal cysts: emphasis on the presence of rupture. AJR Am J Roentgenol 2006; 186: 961-6.

4. Saeed U, Mazhar N. Epidermoid cyst of perineum: a rare case in a young female. BJR Case Rep 2017; 2: 20150352.

5. B. Park, D. Shin, S Kim, H. Jung, G. Son and H. Kim. Perineal squamous cell carcinoma arising from an epidermal cyst: a case report. W. J. of S. Oncology (2018) 16:155 https://doi.org/10.1186/ s12957-018-1442-2.

\section{COMENTARIO}

Los autores publican un caso clínico interesante e infrecuente, sobre una paciente de 75 años con un quiste de inclusión epidérmico en región perianal.

La aparición de un quiste de epidérmico perianal es relativamente baja, siendo más frecuente su aparición en cara, tronco o extremidades. A su vez, también es infrecuente la aparición en una paciente como el caso clínico describe, mujer, y mayor de 50 años.

Si bien es una patología benigna, a veces por su tamaño y localización pueden requerir un diagnóstico diferencial con lesiones malignas de rápido crecimiento.

Felicito a los autores por la presentación y resolución correcta del caso clínico.

Rubén Miravalle

Centro Privado de Cirugía y Coloproctología de la Ciudad de Buenos Aires. C.A.B.A., Argentina. 